\title{
АРХИТЕКТУРНЫЕ, ПЛАНИРОВОЧНЫЕ
}

\section{И ГРАДОСТРОИТЕЛЬНЫЕ РЕШЕНИЯ}

DOI 10.15593/2409-5125/2015.02.02

УДК 711.4-163

\author{
Т.В. Гудзь
}

ООО «Полис консалтинг»

\author{
Д.Н. Генералова, В.С. Петухова
}

Пермский национальный исследовательский политехнический университет

\section{ИССЛЕДОВАНИЕ ВЗАИМОСВЯЗИ ФУНКЦИЙ \\ И ПАРАМЕТРОВ ГОРОДСКИХ КВАРТАЛОВ. РАСЧЕТ ОБЕСПЕЧЕННОСТИ ГОРОДСКИХ КВАРТАЛОВ ПАРКОВОЧНЫМИ МЕСТАМИ В ЗАВИСИМОСТИ ОТ СООТНОШЕНИЯ ОБЩЕСТВЕННОЙ И ЖИЛОЙ ФУНКЦИЙ}

\footnotetext{
В последнее время увеличивается диспропорция между темпами развития автомобилизации и темпами развития дорожной сети. Одна из основных транспортных проблем - дефицит парковочного пространства в городах. В связи с этим возникла необходимость комплексного решения задачи управления парковками. Наиболее проблемной частью города, с точки зрения перенасыщенности городским движением, является его центральная зона. Районы городских центров концентрируют в себе большую часть городской активности, поэтому потребность в офисных помещениях в 1,5-2,0 раза выше в центральной части города, чем на остальных его территориях.

В данной статье рассматривается актуальная на сегодняшний день проблема для всех крупных городов России - организация парковочного пространства в центральной части города. Для выявления взаимосвязей между функциями и параметрами кварталов проводилось комплексное исследование на территории города Перми, состоящее из двух этапов: натурное исследование и эмпирические расчеты. Целью являлось определение максимально допустимой автомобильной емкости показательных городских кварталов в зависимости от доли коммерческой застрой-
} 
ки. Представленное в статье исследование показывает зависимость наполняемости квартала автомобилями от доли жилой или коммерческо-деловой функции этой территории. Приведены результаты двух этапов работы, выявлены основные зависимости, а также даны рекомендации по регулированию сложившейся ситуации в центральной части города.

Ключевые слова: городские функции, парковочное место, коммерческая застройка, баланс территории, максимальное количество автомобилей, дневная миграция населения, офисные помещения.

Проблемы транспорта характерны для стран во всем мире, наиболее ярко они проявляются в образовании пробок, заторов на дорогах, недостаточном количестве стоянок [1]. И в России уже столкнулись с проблемой возрастающего количества автомобилей практически все крупные города - от Санкт-Петербурга до Владивостока [2].

В последнее время увеличивается диспропорция между темпами развития автомобилизации и темпами развития дорожной сети. Дефицит парковочного пространства в городах выдвигает на одно из центральных мест в транспортных проблемах задачу комплексного решения управления парковками. В российских городах обеспеченность местами для хранения автомобилей по месту проживания населения составляет в среднем $35-40 \%$, а обеспеченность местами для парковки автомобилей у объектов тяготения в среднем не превышает 25 \% от требуемого количества. Ситуация осложняется бесконтрольной парковкой транспортных средств, в связи с чем проезжая часть большинства улиц в центральной части городов используется для движения только на $30-50 \%$, а это в свою очередь приводит к соответствующему снижению пропускной способности улично-дорожной сети [3].

Наиболее проблемной частью города, с точки зрения перенасыщенности городским движением, является его центральная зона [4]. Районы городских центров концентрируют в себе большую часть городской активности, поэтому потребность в офисных помещениях в 1,5-2,0 раза выше в центральной части города, чем на остальных его территориях. Это делает данные участки наиболее востребованными для пользователей офисных помещений и, как следствие, повышает потребность людей в парковочных площадях [5]. Помимо этого в центральных городских кварталах зачастую присутствует симбиоз жилья и коммерции (mixed use) - 
первые этажи жилых зданий отдаются под офисные и торговые помещения. Такое сочетание функции в квартале генерирует постоянный транспортный поток на его территорию и, следовательно, возникает потребность в парковке как для местных жителей, так и для работников коммерческих помещений.

На сегодняшний день наибольшим спросом для владельцев личного автомобильного транспорта пользуются свободные дворовые территории и прилегающая к ним улично-дорожная сеть. Площадки для стоянок автомобилей в жилой застройке являются наиболее простым и дешевым типом парковок для хранения автомобилей: из всех видов благоустройства и инженерного оборудования они имеют лишь покрытие [5]. Но такой подход приводит к стихийной парковке, уменьшению пропускной способности улиц и газонам, заставленным машинами.

Для Перми, как и для всех крупных городов Российской Федерации, вопросы современного состояния транспортной инфраструктуры, системы организации дорожного движения и парковочных площадей остаются нерешенными. Это делает особо актуальным данное исследование, связанное с изучением проблем развития и управления парковочными системами. На данный момент ситуация с транспортной системой в центральной части города выглядит просто удручающе. Улицы уже давно не справляются с той интенсивностью транспортного потока, который движется по ним, очень не хватает парковочных мест для посетителей, так как они заняты транспортом сотрудников, работающих в центре города [6].

Цель работы заключалась в изучении проблем, связанных с функционированием автомобильных парковок города Перми, оценке современного состояния обеспеченности парковочными площадями, а также выработке соответствующих рекомендаций [5]. Объектом исследования являются городские кварталы с соответствующей им емкостью автомобильных парковок. Предметом исследования выступают процессы взаимосвязи функций и параметров городских кварталов.

Для определения максимально допустимой емкости автомобильных парковок было выбрано четыре показательных городских квартала города Перми. Выборка осуществлялась по расположению территорий и соотношению функций на них. 
Квартал № 1: ул. Газеты «Звезда»- ул. Советская - ул. Петропавловская - ул. Сибирская - более 50 \% офисных помещений (рис. 1,a);

Квартал № 2: ул. Газеты «Звезда» - ул. Ленина - ул. Петропавловская - ул. Сибирская - $100 \%$ офисных помещений (рис. 1, б);

Квартал № 3: ул. Металлистов - ул. Чехова - местный проезд - местный проезд, переходящий из ул. Инженерная - $100 \%$ жилья (рис. 1, в);

Квартал № 4: Комсомольский пр. - ул. Глеба Успенского ул. Полины Осипенко - ул. Пионерская - более 50 \% жилья (рис. 1, г).

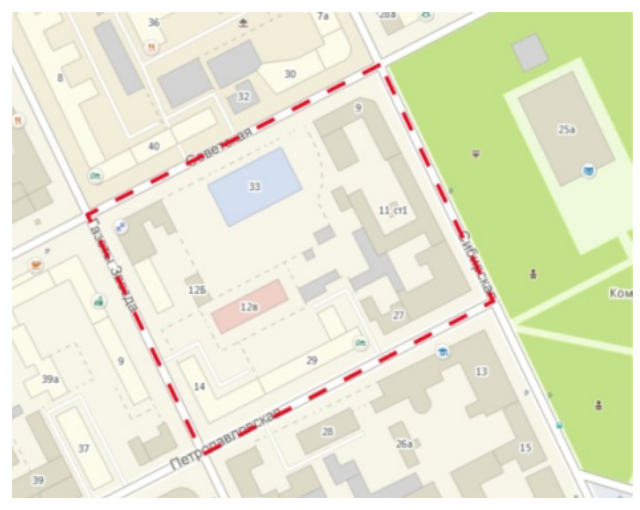

$a$

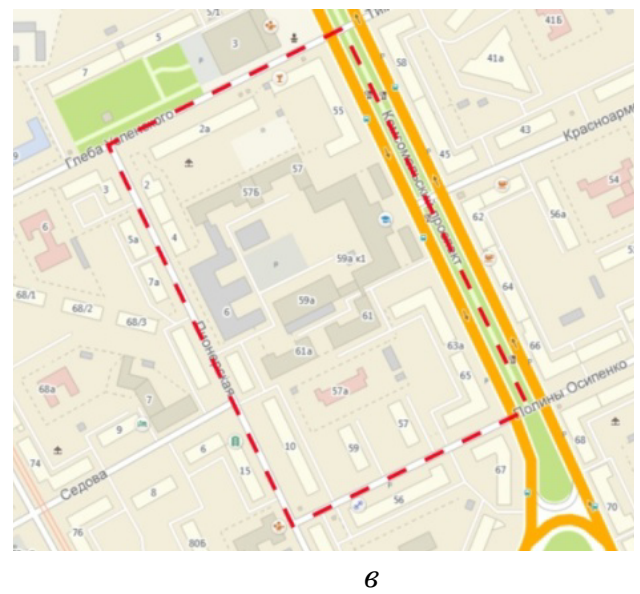

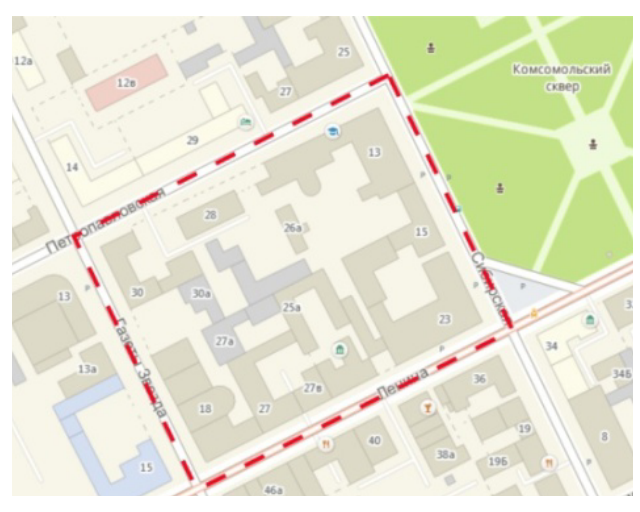

$\sigma$

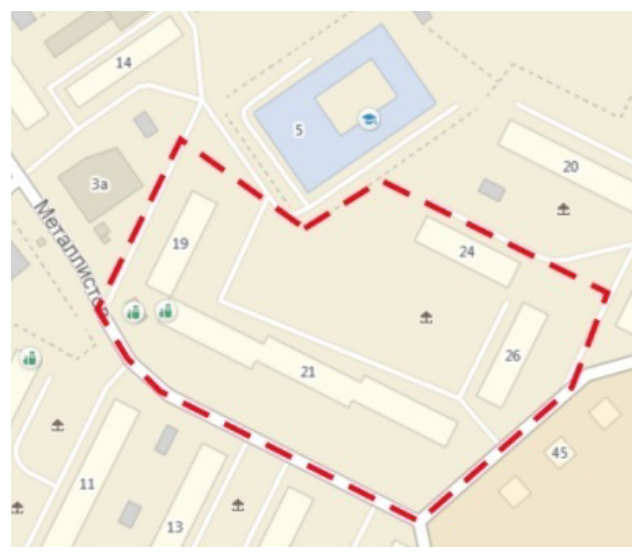

2

Рис. 1. Границы рассматриваемых кварталов 
Анализ исследуемых кварталов проводился на качественном (выявление набора функций) и количественном (процентное соотношение общественной и жилой функций) уровнях [7]. По качественному признаку были выбраны городские кварталы с представленными в них жилой и общественной функциями. Для наибольшей дифференциации исследуемых территорий кварталов на количественном уровне были выбраны городские кварталы с различным соотношением функций.

Работа проводилась в два этапа: натурное исследование выделенных территорий и эмпирические расчеты по нормативным показателям.

Натурное исследование было проведено в будний день в рабочие часы - с 10:00 до 15:00. В результате были получены следующие данные:

- этажность застройки;

- количество этажей, занятых офисными помещениями;

- количество припаркованных автомобилей внутри квартала;

- количество припаркованных автомобилей по периметру квартала.

В кварталах № 1, 2 и 4 основной объем (57\% припаркованных автомобилей) сосредоточен в прилегающей улично-дорожной сети (рис. 2,3 ). Такое соотношение объясняется наличием помещений коммерческо-делового назначения. Важно отметить, что показатели квартала № 2 (ул. Газеты «Звезда» - ул. Ленина - ул. Петропавловская - ул. Сибирская) незначительно отличаются от остальных: количество автомобилей в УДС меньше количества автомобилей, размещенных внутри квартала, это объясняется тем, что парковка по ул. Ленина запрещена (рис. 4).

В квартале № 3 (ул. Металлистов - ул. Чехова - местный проезд - местный проезд, переходящий из ул. Инженерная) процентное соотношение кардинально изменилось - более $91 \%$ от находящихся в квартале машин, припаркованы в дворовом пространстве (рис. 5). Полученный результат был ожидаем, потому как данная территория выбиралась для контраста в сравнении с центральными, насыщенными функциями кварталами.

Полученные данные сведены в табл. 1. Таким образом натурное исследование показало, как распределяется загрузка кварталов транспортными средствами в зависимости от их функционального наполнения. 


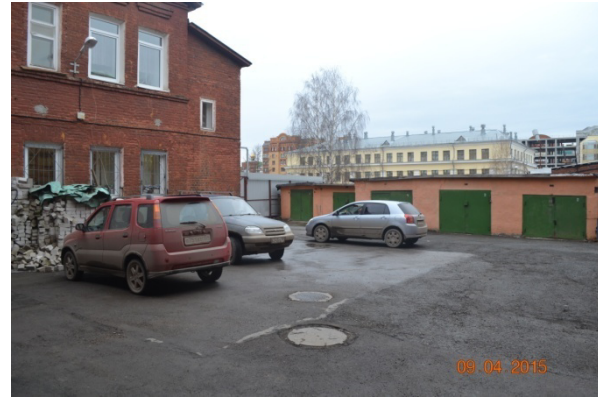

Рис. 2. Двор по ул. Петропавловская низкий процент заполнения территории автомобилями (квартал № 1)

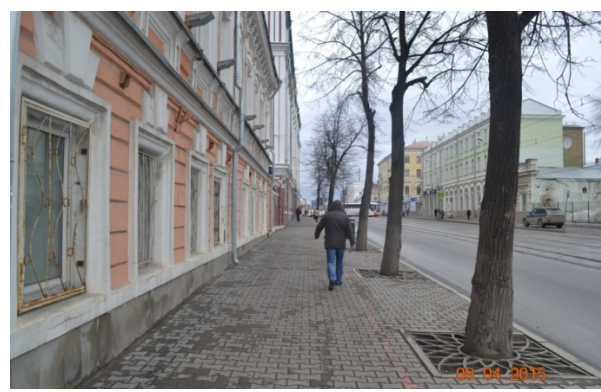

Рис. 4. Улица Ленина - северная граница квартала № 2. Парковка вдоль улиц запрещена

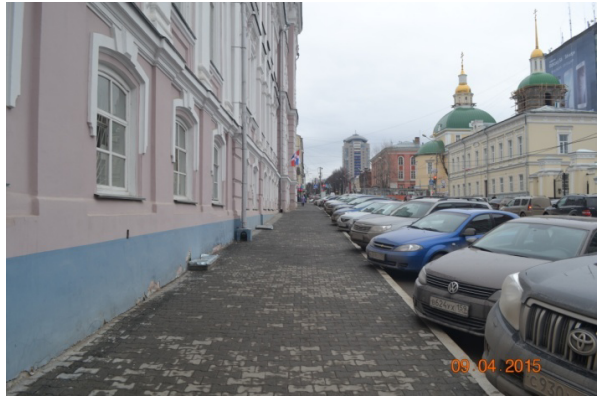

Рис. 3. Улица Газеты «Звезда»большинство автомобилей занимает парковочные места в УДС (квартал № 2)

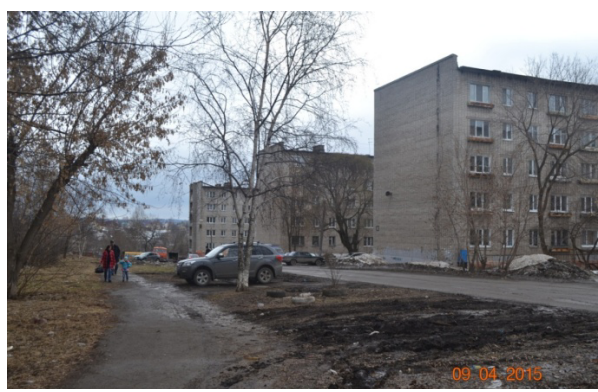

Рис. 5. Улица Металлистов припаркованные автомобили практически отсутствуют (квартал № 3)

Таблица 1

Соотношение количества автомобилей по кварталам

\begin{tabular}{|c|c|c|}
\hline \multirow{2}{*}{ Номер квартала } & \multicolumn{2}{|c|}{ Количество автомобилей } \\
\cline { 2 - 3 } & во дворе & в УДС \\
\hline 1 & 52 & 122 \\
\hline 2 & 89 & 72 \\
\hline 3 & 4 & 41 \\
\hline 4 & 74 & 97 \\
\hline
\end{tabular}

На следующем этапе работы были произведены эмпирические расчеты параметров рассматриваемых территорий. По каждому из кварталов был произведен расчет показателей, приведенных в табл. 2. Полученные количественные значения сведены в табл. 3. 
Таблица 2

Список расчетных показателей исследуемых территорий

\begin{tabular}{|c|c|c|c|}
\hline $\begin{array}{c}\text { № } \\
\Pi / \Pi\end{array}$ & Обозначение & Расшифровка & Формула/Значение/Источник \\
\hline 1 & $S_{\text {кв }}$ & Площадь квартала & \multirow{3}{*}{ Публичная кадастровая карта } \\
\hline 2 & $S_{\text {ж }}$ & $\begin{array}{l}\text { Площадь, занимаемая } \\
\text { жилыми помещениями }\end{array}$ & \\
\hline 3 & $S_{\text {оф }}$ & $\begin{array}{l}\text { Площадь, занимаемая } \\
\text { офисными помещениями }\end{array}$ & \\
\hline 4 & $P_{\text {ж }}$ & $\begin{array}{l}\text { Плотность жилых по- } \\
\text { мещений }\end{array}$ & $P_{\text {ж }}=\frac{S_{ж}}{S_{\text {кв }}}$ \\
\hline 5 & $P_{\text {оф }}$ & $\begin{array}{l}\text { Плотность офисных по- } \\
\text { мещений }\end{array}$ & $P_{\text {оф }}=\frac{S_{\text {оф }}}{S_{\text {кв }}}$ \\
\hline 6 & $S_{\text {благ }}$ & \begin{tabular}{|l|} 
Площадь благоустройства \\
исследуемого квартала
\end{tabular} & $\begin{array}{l}\quad S_{\text {благ }}=S_{\text {кв }} \cdot 0,2^{*} \\
\text { * благоустройство занилает } \\
20 \% \text { от общей площади квар- } \\
\text { тала }\end{array}$ \\
\hline 7 & $S_{\text {застр }}$ & $\begin{array}{l}\text { Площадь застройки ис- } \\
\text { следуемого квартала }\end{array}$ & \multirow{3}{*}{ Публичная кадастровая карта } \\
\hline 8 & $S_{\text {хоз.корп }}$ & $\begin{array}{l}\text { Площадь, застроенная } \\
\text { хозяйственными корпу- } \\
\text { сами }\end{array}$ & \\
\hline 9 & $S_{\text {удс }}$ & $\begin{array}{l}\text { Площадь улично- } \\
\text { дородной сети (УДС) по } \\
\text { периметру квартала } \\
\end{array}$ & \\
\hline 10 & $S_{\text {кв }}^{\text {испр }}$ & $\begin{array}{l}\text { Площадь квартала без } \\
\text { учета площади УдС }\end{array}$ & $S_{\text {кв }}^{\text {испр }}=S_{\text {кв }}-S_{\text {удС }}$ \\
\hline 11 & $S_{\text {внутр. парк }}$ & $\begin{array}{l}\text { Площадь территории, } \\
\text { пригодной для размеще- } \\
\text { ния парковок внутри } \\
\text { квартала }\end{array}$ & $\begin{array}{l}S_{\text {внутр. парк }}=S_{\text {кв }}^{\text {испр }}- \\
-S_{\text {застройки }}-S_{\text {благ }}-S_{\text {хоз. корп }}\end{array}$ \\
\hline 12 & $S_{\text {парк.места }}$ & $\begin{array}{l}\text { Площадь одного парко- } \\
\text { вочного места (с учетом } \\
\text { проездов) }\end{array}$ & $35 \mathrm{~m}^{2}$ \\
\hline 13 & $N_{\text {парк.мест }}^{1}$ & $\begin{array}{l}\text { Расчетное количество } \\
\text { парковочных мест в дво- } \\
\text { ровой территории иссле- } \\
\text { дуемого квартала }\end{array}$ & $N_{\text {парк.мест }}^{1}=\frac{S_{\text {внутр.парк }}}{S_{\text {парк.места }}}$ \\
\hline 14 & $N_{\text {парк.мест }}^{2}$ & $\begin{array}{l}\text { Количество парковоч- } \\
\text { ных мест в УДС }\end{array}$ & Натурное исследование \\
\hline
\end{tabular}

По итогам обработки результатов обоих этапов исследования было получено соотношение числа существующих требуемых парковочных мест, для обеспечения нормального функционирования 
объектов коммерческой инфраструктуры, жилых территорий и пропускной способности улично-дорожной сети для каждого типа квартала. Полученные соотношения представлены в табл. 3.

Таблица 3

Сводная таблица расчетных показателей исследования

\begin{tabular}{|c|c|c|c|c|c|c|}
\hline \multirow{2}{*}{$\begin{array}{l}\text { № } \\
\text { П/ா }\end{array}$} & \multirow{2}{*}{ Показатель } & \multirow{2}{*}{ Ед. изм } & \multicolumn{4}{|c|}{ Номер квартала } \\
\hline & & & 1 & 2 & 3 & 4 \\
\hline 1 & $S_{\text {кв }}$ & $\mathrm{M}^{2}$ & 38481 & 38696 & 18927 & 76610 \\
\hline 2 & $S_{ж}$ & $\mathrm{M}^{2}$ & 13308 & 0 & 29160 & 33768 \\
\hline 3 & $S_{\text {oф }}$ & $\mathrm{M}^{2}$ & 32549 & 39784 & 0 & 33464 \\
\hline 4 & $P_{ж}$ & - & 0,35 & 0 & 1,54 & 0,44 \\
\hline 5 & $P_{\text {oф }}$ & - & 0,85 & 1,02 & 0 & 0,43 \\
\hline 6 & $S_{\text {благ }}$ & $\mathrm{M}^{2}$ & 7696,2 & 7739,2 & 3785,4 & 15322 \\
\hline 7 & $S_{\text {застр }}$ & $\mathrm{M}^{2}$ & 10468 & 11168 & 4207 & 16415 \\
\hline 8 & $S_{\text {хоз.корп }}$ & $\mathrm{M}^{2}$ & 3320 & 2138 & 2747 & 8110 \\
\hline 9 & $S_{\text {удс }}$ & $\mathrm{M}^{2}$ & 2328 & 2334 & 1308 & 5138 \\
\hline 10 & $S_{\mathrm{KB}}^{\text {испр }}$ & $\mathrm{M}^{2}$ & 36153 & 36362 & 17619 & 71471 \\
\hline 11 & $S_{\text {внутр. парк }}$ & $\mathrm{M}^{2}$ & 14668,8 & 15316,8 & 6879,6 & 31624 \\
\hline 12 & $S_{\text {парк.места }}$ & $\mathrm{M}^{2}$ & \multicolumn{4}{|c|}{35} \\
\hline 13 & $N_{\text {парк.мест }}^{1}$ & \multirow{2}{*}{$\begin{array}{c}\text { машино- } \\
\text { мест }\end{array}$} & 419 & 437 & 196 & 903 \\
\hline 14 & $N_{\text {парк.мест }}^{2}$ & & 122 & 72 & 4 & 97 \\
\hline
\end{tabular}

Таблица 4

Итоговые результаты

\begin{tabular}{|c|c|c|}
\hline $\begin{array}{c}\text { Номер } \\
\text { квартала }\end{array}$ & $\begin{array}{c}\text { Существующее количество } \\
\text { машино-мест }\end{array}$ & $\begin{array}{c}\text { Требуемое количество } \\
\text { машино-мест }\end{array}$ \\
\hline 1 & 174 & 541 \\
\hline 2 & 161 & 509 \\
\hline 3 & 45 & 200 \\
\hline 4 & 155 & 1000 \\
\hline
\end{tabular}

Проведенное исследование показало основной объем генерируемого автомобильного транспорта в рассматриваемых кварта- 
лах с различным соотношением жилой и коммерческо-деловой функций.

На данный момент в исследуемых кварталах остро ощущается нехватка организации парковочных площадей для автомобильного транспорта, что сказывается на их обеспеченности парковочными местами:

- наполняемость парковок в прилегающей улично-дорожной сети кварталов № 1, 2 и 4 является $100 \%$-ной;

- обеспеченность парковочными местами внутри исследуемых кварталов:

- в квартале № 1 (более 50 \% площадей занято офисными помещениями) - 32,2\% ;

- в квартале № 2 (100\% занимают офисные помещения) $31,6 \%$;

- в квартале № 3 (100 \% площадей занято жилыми помещениями) $-22,5 \%$;

- в квартале № 4 (более 50 \% - жилые помещения) - 15,5\% .

По полученным данным можно прийти к выводу, что возможная расчетная обеспеченность кварталов парковочными местами абсолютно не соответствует реальному наполнению в силу многих факторов, например, недостаток организации парковок или ее полное отсутствие. Как следствие, возникает проблема хаотичной расстановки автомобилей как внутри, так и по периметру застройки.

Так как основные исследуемые кварталы находятся в центре города, то строительство парковок необходимо для обеспечения мест притяжения населения машино-местами.

На количество припаркованных автомобилей в течение рабочего времени влияет процесс дневной миграции населения. Так, например в кварталах, выполняющих только жилую функцию, данные процессы минимальны, что сказывается на малом количестве припаркованных автомобилей. В кварталах, где совмещены жилая и коммерческо-деловая функции, генерируется плотный транспортный поток как в утреннее, так и в вечернее время.

Следует выделить, что данная проблема решается только комплексно [8]. Решением такого рода проблем может стать создание системы единого городского парковочного пространства, которое будет включать в себя все виды и типы парковочных объ- 
ектов, в том числе подземные паркинги. Ограничение доступа к городу - это способ, направленный на то, чтобы часть водителей отказалась от личного автотранспорта в пользу других альтернативных видов транспорта [9, 10]. Ограничение въезда в центральную часть города (например, платный проезд или система штрафов) и приоритет общественного транспорта также могут стать выходом из сложившейся ситуации.

\section{Библиографический список}

1. Фоменко Г.Р., Сабитова К.Р. Развитие транспортной системы в городах // Вестник Пермского национального исследовательского политехнического университета. Транспорт. Транспортные сооружения. Экология. - 2014. - № 2. - С. 88-96.

2. Проектирование магазинов и торговых центров [Электронный ресурс]. - URL: http://www.usconsult.ru/b 056.html (дата обращения: 15.04.2015).

3. Организация парковочного пространства в общей системе дорожного движения в городах [Электронный ресурс]. - URL: http: //www.dissercat.com/content/organizatsiya-parkovochnogoprostranstva-v-obshchei-sisteme-dorozhnogo-dvizheniya-v-gorodakh \#ixzz3YXQT8426 (дата обращения: 28.04.2015).

4. Третьякова П.А., Клевеко В.И. Современные методы повышения эффективности транспортных систем городов // Вестник Пермского национального исследовательского политехнического университета. Строительство и архитектура. - Пермь, 2012. - C. 101-108.

5. Игнатьев Ю.В. Возведение автомобильных стоянок и парковок в крупных городах // Вестник Южно-Уральского государственного университета. Строительство и архитектура. - 2012. № 17 (276). - С. 68-72.

6. Телегин В.Г., Бурдина С.В., Клевеко В.И. Анализ проблем, вызванных автомобильными заторами и дефицитом парковочных мест в центральной части крупных городов (на примере города Перми) // Вестник Пермского национального исследовательского политехнического университета. Прикладная экология. Урбанистика. - 2014. - № 4. - С. 18-26. 
7. Сосновский В.А., Русакова Н.С. Прикладные методы градостроительных исследований: учеб. пособие. - М.: АрхитектураC, 2006. $-112 \mathrm{c}$.

8. Киричук В.В., Грунев Д.В. Решение проблемы нехватки парковочных мест в г. Великий Новгород [Электронный ресурс] // VII междунар. студ. электрон. науч. конф. «Студенческий научный форум-2015». - URL: http://www.scienceforum.ru/2015/ 883/7275 (дата обращения: 21.04.2015).

9. Телегин В.Г., Клевеко В.И. Проблемы транспортной системы города Перми и пути их решения // Сборник научных трудов SWorld. - Одесса, 2014. - Т. 1, № 1. - С. 11-17.

10. Трофименков Ю.В., Якимов М.Р. Модель формирования эффективной транспортной системы крупного города // Вестник Пермского национального исследовательского политехнического университета. Урбанистика. - 2011. - № 4. - С. 8-16.

\section{References}

1. Fomenko G.R., Sabitova K.R. Razvitie transportnoj sistemy $\mathrm{v}$ gorodakh [Development of transport system in cities]. Vestnik Permskogo natsionalnogo issledovatelskogo politekhnicheskogo universiteta. Transport. Transportnie sooruzheniya. Ecologiya. 2014, no. 2 , pp. 88-96.

2. Proektirovanie magazinov $\mathrm{i}$ torgovykh tsentrov [Design of shops and shopping centers], available at: http://www.usconsult.ru/ b_056.html (accessed 15 April 2015).

3. Organizatsiya parkovochnogo prostranstva $\mathrm{v}$ obshchej sisteme dorozhnogo dvizheniya $\mathrm{v}$ gorodakh [Organisation of parking spaces in the common system of road traffic in cities], available at: http://www.dissercat.com/content/organizatsiya-parkovochnogo-prostranstva-v-obshchei-sisteme-dorozhnogo-dvizheniya-v-gorodakh\# ixzz3YXQT8426 (accessed 28 April 2015).

4. Tret'yakova P.A., Kleveko V.I. Sovremennye metody povysheniya effektivnosti transportnykh sistem gorodov [Modern methods of increasing the efficiency of the transport systems of cities]. Vestnik Permskogo natsionalnogo issledovatelskogo politekhnicheskogo universiteta. Stroitelstvo i arkhitektura. Perm, 2012, pp. 101-108. 
5. Ignatiev U.V. Vozvedenie avtomobilnikh stoyanok i parkovok $\mathrm{v}$ gorodakh [The construction of car parks and parking areas in the big cities]. Vestnik Yuzhno-Uralskogo gosudarstvennogo universiteta. Stroitelstvo i arkhitektura, 2012, no. 17 (276), pp. 68-72.

6. Telegin V.G., Burdina S.V., Kleveko V.I. Analiz problem, vizvannykh avtomobilnymi zatorami i defitsitom parkovochnykh mest $\mathrm{v}$ tsentralnoj chasti krupnykh gorodov (na primere goroda Permi) [Analysis of problems caused by road blocks and lack of parking lots in central parts of cities through the example of Perm]. Vestnik Permskogo natsionalnogo issledovatelskogo politekhnicheskogo universiteta. Prikladnaya ekologiya. Urbanistika, 2014, no. 4, pp. 18-26.

7. Sosnovskikh V.A., Rusakova N.S. Prikladnye metody gradostroitelnykh issledovanij. Moscow: Arkhitektura-S, 2006. 112 p.

8. Kirichuk V.V., Grunev D.V. Reshenie problemy nekhvatki parkovochnykh mest $\mathrm{v}$ g. Velikij Novgorod [Solving the problem of lack of parking spaces in the city of Veliky Novgorod]. VII mezhdunarodnaya studencheskaya elektronnaya nauchnaya konferentsiya «Studenchskij nauchnij forum-2015», available at: http://www.scienceforum.ru/2015/883/7275 (accessed 21 April 2015).

9. Telegin V.G., Kleveko V.I. Problemy transportnoj sistemy goroda Permi i puti ikh resheniya [The problems of the transport system of the city of Perm and their solutions]. Sbornik nauchnykh trudov SWorld. Odessa, 2014, vol. 1, no. 1, pp. 11-17.

10. Trofimenkov U.V., Yakimov M.R. Model formirovaniya effektivnoj transportnoj sistemy krupnogo goroda [The model of formation of an efficient transport system of a large city]. Vestnik Permskogo natsionalnogo issledovatelskogo politekhnichskogo universiteta. Urbanistika, 2011, no. 4, pp. 8-16.

Получено 12.05.2015 


\author{
T. Gudz, D. Generalova, V. Petukhova
}

\title{
INTERRELATION RESEARCH OF FUNCTIONS AND PARAMETERS IN CITY BLOCKS. CALCULATION OF PROVISION CITY BLOCK PARKING SPACES DEPENDING OF THE RATIO OF THE COMMERCIAL AND RESIDENTIAL FUNCTIONS
}

In recent time, there is increasing of disproportion between the pace of motorization development and the pace of road network development, however deficit of parking spaces in the cities brings to one of the central places in transport problems issue of complex parking management. The most problematic part of the city, in terms oversaturation of urban traffic, is its central zone. Central urban districts concentrate a large part of the city activity, so the demand for office space in the 1.5-2.0 times higher in the central part of the city than in the rest of its territory.

This article discusses topical problem for all large cities of Russia - the organization of parking spaces in the city center. To identify the relationship between the functions and parameters of city blocks, there were conducted comprehensive research in the Perm city, that consists of two phases: situ investigations and empirical calculations. The aim was to determine the maximum car density in city blocks, depending on the share of commercial development. The presented research showing number of cars in the block in dependence share from residential or commercial functions of the territory. The results of the two phases of work were presented, the main dependences identified, and recommendations for the regulation of the situation in the central part of the city were given.

Keywords: urban functions, parking space, commercial buildings, the territory balance, the maximum number of cars, the daily migration, offices.

Гудзь Татьяна Васильевна (Пермь, Россия) - канд. экон. наук, генеральный директор ООО «Полис консалтинг» (614000, 2. Пермь, ул. Монастырская, 12, e-mail:gudz.tv@ hotmail.com).

Генералова Дарья Николаевна (Пермь, Россия) - магистрант кафедры архитектуры и урбанистики, бакалавр по специальности «Строительство», Пермский национальный исследовательский политехнический университет (614990, г. Пермь, Комсомольский пр., 29, e-mail: danya.generals@mail.ru). 
Петухова Виктория Станиславовна (Перль, Россия) магистрант кафедры архитектуры и урбанистики, бакалавр по специальности «Пролышленное и гражданское строительство», Перлский национальный исследовательский политехнический университет (614990, г. Перль, Комсомольский пр., 29, е-таil: shakakabat@mail.ru).

Gudz Tatiana (Perm, Russian Federation) - Ph.D. in Economics, General Director of "Polis consulting» (614000, Perm, Monastyrskaya str., 12,e-mail: gudz.tv@hotmail.com).

Generalova Dar'ya (Perm, Russian Federation) - Student of master program of Urban Planning, Perm National Research Polytechnic University (614990, Perm, Komsomolsky av., 29, e-mail: danya.generals@mail.ru).

Petukhova Viktoriya (Perm, Russian Federation) - Student of master program of Urban Planning, Perm National Research Polytechnic University (614990, Perm, Komsomolsky av., 29, e-mail: shakakabat@mail.ru). 